
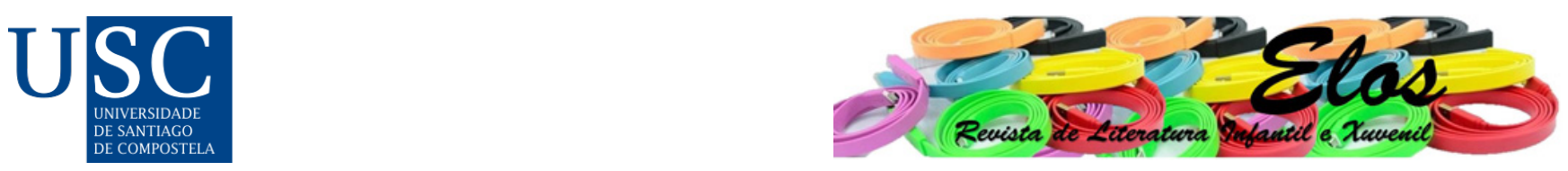

Elos: Revista de Literatura Infantil e Xuvenil, (8), 2021. ISSN-e: 2386-7620

https://doi.org/10.15304/elos.8.7975

Artigos

\title{
A relevância do conhecimento da história da literatura para a infância no processo de mediação leitora
}

La relevancia del conocimiento de la historia de la literatura para la infancia en el proceso de mediación lectora

The relevance of the knowledge of the history of children's literature in the process of reading mediation

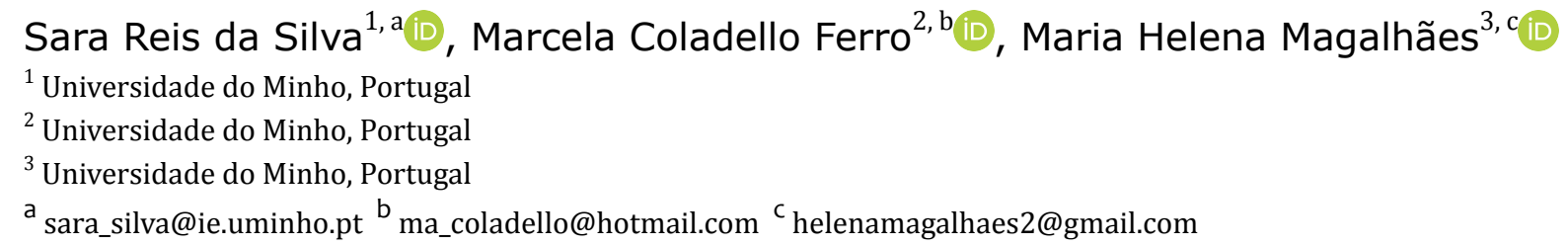

Recibido: 29/09/2021; Aceptado: 08/11/2021

\section{Resumo}

Procede-se, neste estudo, a uma problematização do lugar e da relevância da História da Literatura no âmbito da formação de mediadores de leitura, bem como da qualidade das suas práticas. A partir de uma abordagem genérica da obra de António Torrado (1939-2021), seguida de uma referência analítica a alguns dos seus textos narrativos que compõem o vasto universo das retextualizações, revisitações ou reescritas do acervo literário tradicional oral para a infância, procura-se concluir acerca da pertinência do conhecimento da História da Literatura para o aprimoramento de práticas de mediação de leitura empreendidas por mediadores verdadeiramente capacitados para tal, ou seja, mediadores cujo intertexto leitor (Fillola, 2001) seja também diacronicamente rico e preenchido de referências literárias diversas em termos de data ou época de edição, autoria, modo ou género literário, estilo, entre outros.

Palavras-chave: literatura para a infância; história da literatura; mediação leitora; António Torrado

\section{Resumen}

En este estudio se procede a problematizar el lugar y la relevancia de la Historia de la Literatura en la formación de los mediadores de lectura, así como la calidad de sus prácticas. A partir de una aproximación genérica a la obra de António Torrado (1939-2021) y el breve análisis de algunos de sus textos narrativos que conforman un vasto universo de retextualizaciones, revisitaciones o reescrituras de la literatura de tradición oral para la infancia, se busca aportar conclusiones acerca de la relevancia del conocimiento de la Historia de la Literatura para el perfeccionamiento de las prácticas de mediación lectora realizadas por mediadores realmente capacitados para ello; es decir, mediadores cuyo intertexto lector (Fillola, 2001) sea también diacrónicamente rico y esté repleto de diversas referencias literarias en relación con la fecha o época de edición, autoría, modo o género literario, estilo, entre otros. 
Palabras clave: literatura para niños; historia de la literatura; mediación lectora; António Torrado

\begin{abstract}
In this study, we aim at problematize the place and relevance of the History of Literature in the context of training reading mediators, as well as in the quality of their practices. From a generic approach to the literary work of António Torrado (1939-2021), followed by an analytical reference to some of his narrative texts that make up the wide universe of retextualizations, revisitations or rewritings of the traditional oral literary heritage for children, conclude on the relevance of the knowledge of the History of Literature for the improvement of reading mediation practices undertaken by truly capable mediators, that is, mediators whose reader intertext is also diachronically rich and filled with several literary references in terms of date or publishing period, authorship, literary mode or genre, style, among others.
\end{abstract}

Keywords: children's literature; literary history; reading mediation; António Torrado

\title{
1. INTRODUÇÃO
}

Sistema específico e marcadamente polimórfico no conjunto literário polissistémico, a literatura que tem na criança o seu preferencial destinatário extratextual tem ganho relevância/ reconhecimento social, no contexto educativo e, em concreto, na própria academia ou na investigação que progressivamente tem preconizado um posicionamento consentâneo com paradigmas teórico-metodológicos assentes na interdependência das quatro disciplinas a partir das quais se conformam os Estudos Literários: Teoria, Crítica, História e Literatura Comparada (Villanueva, 1994). Acresce o facto da pesquisa especializada em torno da literatura de potencial recepção infantil, em concreto, no âmbito ibérico (mas não apenas) ter enveredado, ainda, a partir da imprescindível compaginação destes âmbitos, pela valorização das seguintes linhas, devidamente estipuladas, desde 2004, pelo grupo de investigadores membros da Red Temática LIJMI: 1. História (periodização e géneros; história dos sistemas literários - produção, recepção e mediação; bibliografias e dicionários; ilustração); 2. Teoria e Crítica (modelos teóricos; estudos de obras, géneros e autores; cânone; tradução; imagem; literatura de transmissão oral; tecnologias da informação e da comunicação; ideologia e valores; edições críticas); 3. Literatura comparada (estudos comparativistas: estilos, géneros e temas; relações diacrónicas e sincrónicas; multiculturalismo); 4. Leitura (promoção e mediação da leitura; hábitos de leitura; leitura da imagem e cultura visual; formação do leitor literário/competência literária; aplicações educativas da Literatura Infantil e Juvenil).

No âmbito da formação de mediadores de leitura, as quatro disciplinas enunciadas por Villanueva (1994), assim como as linhas que vimos de registar, propõem ou proporcionam, na verdade, um conjunto de instrumentos teóricos e histórico-críticos absolutamente fundamentais para o desenho e posterior implementação de qualquer projecto de promoção da leitura e/ou educação literária. Neste contexto, acentuamos a relevância do conhecimento alargado da História da Literatura para a Infância e lembramos, a este propósito que, no caso português, além da obra Capítulos da História da Literatura Portuguesa para a Infância (2016), que, efectivamente, não possui um carácter diacrónico, o último estudo historiográfico editado data de 2001, sendo uma actualização de uma breve monografia de Natércia Rocha editada em 1984. Referimo-nos, em 
concreto, a Breve História da Literatura para Crianças em Portugal (2001, Caminho). Uma rápida nota, ainda, para assinalar que, em Portugal, contamos apenas com as seguintes edições de carácter histórico e panorâmico: Esther de Lemos (1972). A Literatura Infantil em Portugal. EN-DGEP; Maria Laura Bettencourt Pires (1983). História da Literatura Portuguesa para Crianças. Vega IN-CM; José António Gomes (1997). Para uma História da Literatura Portuguesa para a Infância e a Juventude. MC - IPLB.

Nestes estudos historiográficos, cada um no seu tom e forma, ensaia-se um mapeamento, quase sempre, diacrónico, da literatura portuguesa para a infância, propondo-se uma periodização, fazendo sobressair determinados autores e certos títulos ou textos, situados cronologicamente, enfatizando certas tendências, assim como a valorização de alguns modos ou géneros literários. Trata-se, pois, de um conjunto de estudos que oferecem visões historiográficas, fundamentais, no nosso entender, para o entendimento do devir histórico da literatura, visões sem as quais consideramos que a formação literária fica incompleta ou comprometida, porque, na realidade, esta "precisa integrar dois esteios: por um lado, um saber de natureza predominantemente narrativa e concretizante, a história literária, produtora de imagens das literaturas nacionais segundo [as] suas realizações no espaço e no curso do tempo; por outro, a teoria da literatura, um conhecimento de índole universalista e abstratizante, em que, por consequência, em vez da exposição narrativa própria da história literária, predomina o puro manejo dos conceitos" (Souza, 2014, p. 105). Por conseguinte, a História da literatura representa um "fundamento insubstituível para a formação de um especialista em literatura. Mesmo o seu mais duro opositor - acreditamos - há de convir que, sem o domínio de uma espécie de mapa do tempo, é impossível orientar-se no território do literário" (Souza, 2014, p. 107).

E essa espécie de mapa do tempo ou o domínio dessa História da Literatura é também uma condição sine qua non para a formação dos mediadores de leitura e para o desenvolvimento de uma prática de mediação leitora responsável, sustentada, criativa e inovadora.

Ser detentor de uma vasta cultura literária e conhecer, portanto, a História da Literatura, passa pela familiarização, por exemplo, com o acervo literário tradicional oral, quer das suas formas narrativas, quer das suas formas poético-líricas, na medida em que estas compõem uma espécie de húmus da escrita autoral, relevantes hipotextos da literatura para a infância, plasmando-se diversamente neste sistema específico. As suas ressonâncias ou os ecos intertextuais que nos textos de autor especialmente dirigidos ao destinatário extratextual infantil se pressentem merecem atenção e um trabalho de leitura e análise crítica que, inevitavelmente, reclama o recuo no tempo, o reconhecimento do seu lugar na História literária e o seu cotejo com as manifestações literárias com autoria definida que chegam, na contemporaneidade, aos leitores mais jovens.

Este é, com efeito, um caminho exigido ao mediador de leitura que, almejando uma acção fundamentada e situada, terá, inevitavelmente, de ser detentor de um sofisticado "intertexto leitor" (Fillola, 2001), cronológica ou historicamente organizado, por forma a uma mobilização que potencie os nexos históricos e as relações plurais entre os textos, na medida em que essa interrelação ou esse diálogo se afigura muito relevante na conformação de uma cultura literária precoce no que diz respeito aos pequenos leitores.

Sinteticamente, e considerando o que defende Gomes (2012),

É que não é possível promover a leitura sem um conhecimento da História literária, dos rumos passados e atuais, das diferentes modalidades genológicas patentes na escrita para crianças e jovens, bem como dos caminhos percorridos pela ilustração. Não é possível, enfim, promover a leitura sem ler - obviedade que qualquer leitor julgaria dispensável, mas que paradoxalmente ou talvez não, importa continuar a enfatizar nos tempos que 
correm. Tão pouco é possível mediar a leitura sem recurso prévio ou concomitante a um discurso crítico produzido por estudiosos e investigadores - e não apenas promovido pela espuma mediática e blogosférica -, e sem um saber mínimo sobre o panorama diacrónico desta criação literária e artística, o qual permita relativizar juízos apressados sobre o presente e suas pretensas inovações, e avaliar os retrocessos que nele também, por vezes, se verificam. (Gomes, 2012, p. 12)

\section{O MEDIADOR DE LEITURA: PERFIL E/OU (NECESSÁRIA) FORMAÇÃO}

Sobre o mediador de leitura, Pedro Cerrillo regista, por exemplo, o seguinte: "El profesor/ mediador es, de algun modo, un agente, un actor que intermedia en el camino que va del libro al lector escolar, pero formalmente, es decir mediante el contacto directo" (Cerrillo, 2010, p. 122). Assim, este investigador espanhol (2010) define os mediadores que se encontram ligados ao ensino como ponte, um elo entre o livro e o leitor mediante a função simultaneamente social e educativa da literatura, que é formar os leitores por prazer. Em todo esse processo, já nas primeiras leituras, é a voz do mediador, desejavelmente rica, do ponto de vista do reportório literário que, em si, guarda e pretende partilhar, que permite a entrada significativa e precoce da criança na cultura literária.

É certo que a figura do mediador, em Lluch (2003), por exemplo, adquire grande importância no esquema comunicativo especificamente atinente à literatura de preferencial recepção infantil, mediada pela relação social que, historicamente, o adulto e a criança mantêm. Importa ter em vista que, diferente de outras literaturas, a literatura para a infância, inserida na teoria dos polissistemas, convocada por Zohar Shavit (1986), prevê esse duplo leitor. Note-se que o adulto intervém inclusivamente nas leituras infantis, aprendizagens e criações literárias.

Levando em linha de conta a ideia de mediação relacionada com um objectivo social, atribuído principalmente à escola, para Felipe Munita (2014), trata-se de ajudar a criança a progredir como leitor, ao planear uma atividade de mediação, para que se possa alcançar uma compreensão mais profunda de um livro ou, mais especificamente, de um texto literário. Assim, quando falamos de mediação da leitura, referimo-nos a esse exercício orientador ou a esse "labor mediador", destacado pelo estudioso que vimos de citar, um espaço de encontro entre práticas pedagógicas, sistemas de crenças e trajectórias pessoais de leitura.

Na conformação do perfil do mediador, ganham especial relevância o prazer de ler e a capacidade de o transmitir, contagiando emotivamente aqueles com que se encontra, por meio dos livros e da leitura. 0 mediador é também alguém que nutre um gosto ou um interesse especial pelos livros, pela literatura e pela leitura, mas que deve, necessariamente, possuir uma formação literária (que engloba saberes provenientes das quatro disciplinas supramencionadas nas considerações iniciais desta sucinta abordagem), didáctica e psicológica. Além disso, será detentor de competências que lhe possibilitem aceder à informação, num gesto contínuo e empenhado de autodidatismo, que lhe permitirá manter-se a par das novidades editoriais, bem como tomar contacto com bases de dados, repertórios, bibliotecas, blogues, entre outros. Segundo Cerrillo (2009), urge que os mediadores se distingam pelo facto de se revelarem "sólidamente formados y com los médios necessários para cumplir dignamente su responsabilidade, porque son quienes van a propiciar el contacto de los lectores com los libros desde las primeras edades" (Cerrillo, 2009, p. 96). Assim, o mediador deve formar-se ao longo de um "processo largo, organizado, coherente y comprometido, em el que se unirán conocimientos generales y específicos, competências profesionales, espíritu crítico, capacidade para la intervención comunicativa, creatividad, critérios socializadores, humanismo y, hoy también, capacidade para entender y atender la diversidade cultural" (Cerrillo, 2009, p. 
99). Acrescenta, ainda, que este processo, que apenas por vontade própria do mediador poderá cumprir-se verdadeiramente, é que tornará possível que reúna as atitudes, aptidões e requisitos exigidos para desenvolver a sua importante tarefa de mediação leitora. Note-se que, no elenco de requisitos apresentados por Cerrillo, consta o seguinte: "La contextualización histórica de la Literatura Infantil” (Cerrillo, 2009, p. 100).

Para tanto, é necessário muito mais do que conhecer alguns punhados de livros ou acompanhar os bestsellers infantojuvenis em evidência, fixando-se, apenas, por exemplo, naquilo que os media publicitam ou naquilo que certos espaços comerciais, como certas cadeias de livrarias, colocam em destaque, lançando mão, até, de um forte merchandising. É imprescindível que, para "educar literariamente" (Rechou, 2013) e oferecer livros às crianças, se conheça a História da Literatura. Para esta investigadora galega, "é fácil constatar que a maior parte dos mediadores non coñecen ainda hoxe cómo se xestaron as Literaturas Infantis e Xuvenis das súas proprias nacións" (Rechou, 2013, p. 63).

Como poderá, assim, o mediador de leitura, investido de uma reconhecida responsabilidade, promover a leitura da literatura infantil, ou contribuir para a construção de uma cultura literária, sem conhecer a História, os processos que engendram o seu passado, o seu presente e, até, o seu futuro? Não é possível transmitir o gosto, o prazer pela leitura de Monteiro Lobato, a exemplo, no caso brasileiro, sem ter conhecido o prazer de viver (e reviver com a leitura compartilhada) as aventuras do Sítio. Na verdade, o processo de mediação, assim como de recepção, tornar-se-á tanto mais fechado e restrito quanto se apresentar limitad o o universo de leituras e o conhecimento de textos matriciais pertencentes a determinada Literatura. Tenhamos como exemplo - e sobre esta questão, na secção seguinte deste estudo, versar-se-á de forma mais sistemática este tópico, situando no universo da escrita da autoria de António Torrado - a relevância do mediador já ter tomado contacto com a narrativa em verso ou com o rimance tradicional sobejamente conhecido intitulado "Lá Vem a Nau Catrineta", antes de mediar a leitura dos textos contemporâneos "A Nau Luareta" (em A Guitarra da Boneca (1983), de Matilde Rosa Araújo (1921-2010)) ou A Nau Mentireta (1991), de Luísa Ducla Soares (Lisboa, 1939). Outro exemplo reside nas possibilidades interpretativas (e fruitivas, também) ou na abertura recetiva que uma familiarização por parte do mediador com o conto matricial "O Coelho Branco", texto patente em Contos Populares Portugueses (1979), de Adolfo Coelho (1847-1919), sobejamente difundido desde a primeira infância, antes de proporcionar aos leitores mais novos, aquando de um gesto de mediação em contexto formal e informal, uma leitura de edições contemporâneas, ou seja, reconfigurações com um fim lúdico, tais como: O Urso e a Formiga (1973), de Luísa Ducla Soares; A Verdadeira Vida da Formiga Rabiga (2001), de Violeta Figueiredo; ou O Coelhinho Branco e a Formiga Rabiga mais a Cabra e a sua Barriga (2008), de João Pedro Mésseder (Porto, 1957). A congregação de base intertextual de títulos epocal e autoral diversos, testemunhado inevitavelmente sinais dos tempos e distintas sensibilidades estéticas, além de discursos estéticos variados, afigura-se um meio potencialmente favorecedor da promoção de uma cultura literária.

Dessa forma, diante da tarefa mediadora, situada histórica e socialmente, defendemos que se adote a literatura para a infância no âmbito escolar por meio de um discurso crítico, necessariamente sistemático. Gemma Lluch (2003) propõe um modelo de análise focalizada nos aspectos mais presentes na literatura infantil. A análise de primeiro nível: pragmática; de segundo nível: antes do texto - paratextos; e de terceiro nível: a narração. Para ela, o mediador deve contextualizar historicamente as leituras, não permanecendo apenas no primeiro nível de análise das informações, pois realizará uma leitura ingénua. Lluch regista, portanto, que: 


\begin{abstract}
Sin las informaciones las informaciones que nos ofrece este primer nivel de análisis, la lectura ingenua que realizamos de La vuelta al mundo en 80 días es la de la historia de un hombre empeñado en ganar una apuesta, 0 leeremos Mujercitas como un relato ramplón de cuatro hermanas y de pequeñas aventuras. Pero las informaciones pragmáticas, nos permitirán ahondar y una lectura crítica de estas obras nos ofrecerá en el primer caso la lucha del hombre del siglo XIX, que conquista el mundo e inventa nuevas tecnologías, contra la naturaleza y en el segundo, nos permitirá ver una lectura subversiva en la cual una adolescente, a pesar de las estrictas normas del momento histórico, decide dedicarse a escribir. (Lluch, 2003, p. 5)
\end{abstract}

Este método auxilia os mediadores a analisar os textos e a "rodear" os jovens leitores de materiais literários de qualidade, pautados, também e na verdade, pela diversidade ou pluralidade dos seus códigos estéticos, designadamente do policódigo literário, do registo ilustrativo ou imagético e, até, em certos casos (por exemplo, nos livros-objecto) da própria linguagem gráfica ou material do exemplar editado.

Ao oferecer diferentes obras literárias aos mais jovens, Rechou (2013, p. 54) considera que "o mediador tem como instrumento a "Educação literaria, unha metodoloxía que permite planificar a lectura [...]". A autora refere-se a práticas, atitudes, conteúdos e memórias que visam ativar os intertextos e enciclopédias individuais, para que se possa interpretar os textos, permitindo a experiência do prazer da leitura literária e a inserção numa cultura literária.

A mesma investigadora acentua o facto de que "Para levar a cabo os obxectivos da educación literaria e para cumprir as súas funcións, o mediador debe partir de coñecementos transmitidos a partir de fontes básicas como as "Histórias da Literatura" (Rechou, 2013, p. 57). Apenas assim poderá desempenhar com propriedade, rigor e eficácia as funções que lhe são inerentes, designadamente: criar e fomentar hábitos de leitura estáveis; ajudar a "ler por ler", diferenciando a leitura obrigatória da leitura voluntária, ou seja, potenciar a leitura voluntária; orientar a leitura extra-escolar; promover, coordenar e facilitar a seleção de leituras, segundo o perfil e os interesses dos destinatários; preparar, desenvolver e avaliar as actividades de mediação de leitura; e realizar cânones literários (de aula, por exemplo) e não literários, a partir de Histórias da Literatura, estudos sectoriais ou estudos repertoriais.

Logo, encontrar um ambiente escolar mediador é fundamental para iniciar uma vida de leituras literárias, inclusive para dar continuidade a uma relação com a literatura, que começa pela oralidade, desde o nascimento da criança, "tanto, el niño iniciará el periodo escolar (que es su primer contacto con la cultura "oficial") con el conocimiento de canciones, cuentos, álbumes ilustrados, juegos mímicos, retahílas de diverso tipo, oraciones y sinsentidos, dichos o cantados por los mediadores adultos [...]" (Cerrillo, 2016, p. 38).

\title{
3. O LUGAR E A PRESENÇA DO ACERVO LITERÁRIO TRADICIONAL ORAL NA LITERATURA PARA A INFÂNCIA: O CASO DE ANTÓNIO TORRADO
}

A recuperação multímoda de expressões literárias que podemos apelidar de matriciais (por se apresentarem como origem, base ou ponto de partida e por possuírem uma essência geradora), em concreto de formas narrativas e de formas poético-líricas da tradição, tem representado uma das tendências mais evidentes no universo da escrita e da edição para a infância.

Num misto de tradição e contemporaneidade, entretecido de múltiplos e, por vezes, difusos nexos que se afundam na espessura dos tempos, emergem estimulantes textos literários que apresentam vínculos intertextuais que reclamam "a memória do sistema literário" e demandam 
uma "relação de intersecção semioticamente produtiva" entre o emissor e o receptor dos textos (Silva, 2020, p. 265), o que nos remete para o já referido importante papel do mediador de leitura no estabelecimento de uma relação de compreensão e fruição da criança no convívio com os textos literários.

Reflectir sobre os modos como se recupera e (re)integra o tradicional numa época marcada pela globalização e pelo esbatimento de fronteiras culturais permite confirmar que uma grande parcela da literatura contemporânea estabelece níveis de intertextualidade com a literatura tradicional (Pires, 2007), fonte inesgotável de inspiração, influenciando, a diferentes níveis e praticamente desde a sua origem, a produção literária para a infância (Gomes, Ramos e Silva, 2010).

Importa, também, referir que a contínua criação de reelaborações diversas de textos tradicionais possui grande potencial educativo nas vertentes estético-literária, lúdica, simbólica e afectiva, estimulando projectos de leitura bem estruturados, promotores da literacia crítica e da competência leitora.

Mais próximos ou mais distantes da matriz tradicional, inúmeros autores contemporâneos continuam a revisitar e a reescrever contos da tradição oral, enriquecendo o panorama literário e dando origem a trabalhos de investigação fundamentalmente dedicados ao estudo das relações de diálogo intertextual que se estabelecem entre narrativas tradicionais e as suas reescritas. 0 caso de António Torrado (Lisboa, 1939-2021) e das suas diversas revisitações criativas de textos originários da tradição oral afigura-se verdadeiramente modelar, quer pelo elevado número de exemplares que, ao longo de cerca de três décadas, publicou quer essencialmente pelos processos (re)criativos singulares e pelos usos da matéria literária tradicional que, de forma muito peculiar, concretiza e que demarcam esses textos de outros assinados por outros autores que enveredaram igualmente pela mesma via.

Inspirando-se diretamente no imaginário tradicional, no pensamento antropomórfico que humaniza todos os seres e num registo lúdico, bem ao gosto da imaginação das crianças, este autor carismático constrói narrativas singulares, propondo a reflexão sobre as virtudes e as imperfeições humanas ao mesmo tempo que transmite às novas gerações importantes referências da cultura tradicional. Embora conserve características do contexto histórico e sociocultural que a gerou, mantendo viva a corrente da oralidade e da força mágica da palavra criteriosamente escolhida, a escrita de António Torrado não se limita ao legado da tradição e permite ao leitor o acesso ao jogo criador e ao fluir natural do imaginário onde diferentes peças se organizam num inusitado puzzle intertextual com qualidade literária e recreativa.

A sua extensa e diversificada obra, alicerçada na memória literária, pela via da tradição oral ou da literatura institucionalizada, expressa uma capacidade imaginativa invulgar, um sentido de humor inigualável e uma habilidade única para prender a atenção do leitor. Ao jeito de um simples contador de histórias, Torrado interpela o leitor, dialoga com ele, compelindo à reflexão sobre questões universais como os conflitos de poder, os preconceitos, os comportamentos discriminatórios, a mesquinhez humana, a injustiça social, a arbitrariedade no uso do poder e a defesa de valores assentes na liberdade, na fraternidade, no respeito pela natureza, pelos animais e por tudo o que nos humaniza.

Sensível perante as injustiças e as desigualdades sociais, António Torrado expressa na sua obra preocupações relevantes, próprias de um agente empenhado na mudança social, em momentos muito diferentes da realidade sociopolítica portuguesa. Entre os seus livros editados antes do 25 de Abril, destacamos $O$ Veado Florido (1972), que integrou a lista de honra do International Board on Books for Young People, onde sob a forma de parábola infantil se exprimem os anseios de 
liberdade sentidos nos últimos anos da ditadura salazarista e marcelista (Gomes, 2017). Revelando uma preocupação premente com temáticas de natureza social e política, é possível integrar este autor numa geração de figuras literárias que tornaram possível a transição da ditadura para a democracia e que podemos apelidar de "Resistência". Após o 25 de Abril de 1974, publicou, em Portugal, um elevado número de obras literárias, que foram traduzidas para a língua galega, dando voz à literatura dramática e às reescritas de narrativas da tradição oral através de versões muito criativas e reconhecidas como uma forte influência na consolidação da literatura galega (Rechou \& Silva, 2017).

Considerado um dos mais talentosos escritores para a infância, António Torrado é, simultaneamente, autor de um sólido, fecundo e prestigiado projeto literário, cultural, dramatúrgico e educativo, impulsionador de importantes reflexões sobre políticas de ensino e de promoção da leitura e da educação literária. A sua longa e diversificada obra, destinada quer a adultos, quer a crianças, abarca todos os modos literários, numa multiplicidade de géneros e temáticas, tornando-o um nome incontornável no panorama literário português (Ramos, 2017), galardoado com vários prémios, dos quais se destaca o Grande Prémio de Literatura Infantil Calouste Gulbenkian pelo conjunto da sua obra, em 1988.

A presença dos modos lírico, narrativo e dramático na sua obra, a variedade e pertinência temática, o domínio dos códigos técnico-compositivos e a sensibilidade pedagógica aliada a um profundo conhecimento do imaginário infantil, tornam este autor uma singular referência no universo da escrita para a infância. De salientar que as formas poético-líricas apresentam trocadilhos, jogos de palavras e fonemas de difícil articulação, ao jeito dos trava-línguas, partindo, não raras vezes, de realidades e objetos que associa de forma improvável e surpreendente, com humor, recusando o simplismo ideológico e fazendo apelo à imaginação e ao espírito crítico dos pequenos leitores.

Acresce referir que a escrita de António Torrado revela um cuidado aprimorado com a linguagem e um investimento estilístico que perscruta as palavras nas suas facetas sonoras e semânticas. Aliterações, repetições, onomatopeias, personificações, metáforas, comparações são recursos interessantes da sua poética que se manifestam também na prosa, articulando de forma sagaz forma e conteúdo, num ritmo marcado pelo lúdico, pela ironia, pelo humor e por um tom jovial que abraça o leitor num sorriso cúmplice e comprometido com a alegria e a harmonia universal atemporal. 0 tom poético, o ritmo e a rima marcam também a narrativa e o texto dramático, numa simbiose invulgar com as marcas da oralidade (Silva, 2017) e de uma cultura ancestral que faz parte do nosso património imaginário coletivo. 0 leitor é acompanhado numa viagem ao passado, impelido a demorar o olhar num vocabulário por vezes desusado e a interrogar a realidade extra e intratextual para, de novo, regressar à contemporaneidade iluminado por uma liberdade interpretativa fecunda que lhe é oferecida e que, no caso dos pequenos leitores, reclama a mediação leitora.

A leitura de obras de autores de reconhecida qualidade literária associada a uma sólida mediação leitora tem sido apontada como prática que contribui para a formação de leitores críticos preparados para o exercício de uma cidadania global. Um cânone literário para a infância estimulador deste leitor, progressivamente autónomo e crítico, deverá possibilitar o acesso aos intertextos fundamentais do património de uma memória coletiva (Azevedo, 2006), o que nos remete para a importância da presença dos clássicos na educação literária (Calvino, 2015; Sáez, 2013) e para a necessidade de conjugar, com harmonia, tradição e inovação. Nesta linha de pensamento, a escrita de António Torrado, um "irrecusável clássico contemporâneo" (Roig Rechou, 2016) que ajuda a preservar a memória da cultura popular com novas roupagens e temáticas 
hodiernas (Gomes, Ramos e Silva, 2010) emerge com grande acuidade, tornando-o um autor modelar com lugar de destaque nos currículos escolares e no Plano Nacional de Leitura; um autor cuja produção literária de destinatário infantil importa conhecer e (re)visitar para aprofundar os vários níveis de leitura e as dinâmicas de intertextualidade que augura, conformadoras - na nossa perspectiva - de uma potencial cultura e/ou educação literária.

\section{CONCLUSÕES}

No breve estudo que agora concluímos, procurámos problematizar sucintamente a relevância da História da Literária na formação de mediadores de leitura, assim como no seu importante exercício de mediação, interseccionando, portanto, três tópicos passíveis de reflexão: a História da Literatura, a mediação de leitura e o perfil do mediador e, ainda, a escrita de autor como deriva da literatura tradicional oral. Para tal, começámos por acentuar a importância da História da Literatura, tantos nos estudos literários, como no processo de formação do mediador de leitura, para, de seguida, após um desenho genérico do perfil reclamado a um mediador de leitura, focarmos a obra de António Torrado, em concreto na sua vertente especialmente alicerçada ou alavancada em manifestações literárias de origem tradicional revisitadas diversamente pelo autor, na linha do que, aliás, vem sendo apontada como uma das tendências contemporâneas da literatura portuguesa que tem no leitor infantil o seu potencial destinatário. Note-se que António Torrado, um dos nomes cimeiros da literatura infantil portuguesa, integra um grupo de escritores empenhados e prolíficos (Luísa Ducla Soares, Maria Rosa Colaço ou Alice Vieira, por exemplo, fazem parte desta geração) que, nos anos imediatamente após o 25 de Abril de 1974 e com a implantação da democracia, muito contribuíram para a promoção da leitura e para a formação de leitores, tanto a partir da sua própria escrita ficcional, de autor, como da recuperação e reescrita de textos do acervo tradicional oral ou da própria coordenação de coleções (como a "Lagarto Pintado", da Plátano) em cujos volumes é, por vezes, possível encontrar importantes peritextos informativos dirigidos a pais e a educadores, contendo um série de indicações relativas aos "modos de ler" de certos textos.

Convocámos, portanto, para a presente reflexão justamente o caso da produção literária de António Torrado, em concreto da parcela que se enraíza no acervo literário tradicional oral, como mencionámos, ou seja, em intertextos considerados como fundamentais e tornados canónicos (Azevedo, 2003) no sistema literário que tem na criança o seu preferencial destinatário extratextual, e que resulta em objectos tidos como relevantes retextualizações ou reelaborações literárias na constituição de um repertório literário individual. Esta opção justifica-se pela imprescindibilidade do conhecimento aturado por parte do mediador de leitura das matrizes literárias, pilares históricos, portanto, que originaram objectos literários renovados ou que apresentam novas roupagens. 0 processo de leitura - e, naturalmente, de mediação de leitura - será tanto mais profundo quanto melhor se dominarem e entenderem as raízes ou as origens históricas de cada texto, na medida em que tal conhecimento facilitará um exercício de mediação mais informado, envolvido/envolvente e vivo, além de possibilitar a conformação e o alargamento do intertexto leitor do jovem recetor, o que, naturalmente, representará um determinante contributo para a sua educação literária. 


\section{Referências bibliográficas}

Azevedo, F. (2003). Intertextos fundamentais na constituição de um cânone literário para a infância. Malasartes - Cadernos de Literatura para a Infância e a Juventude, 13, 13-17.

Calvino, I. (2015). Porquê ler os clássicos?. Editora Dom Quixote.

Cerrillo, P. C. (2009). Sociedad y Lectura. La Importancia de los Mediadores en Lectura. Em Vv.Aa., Formar Leitores para Ler o Mundo (pp. 95-104). Casa da Leitura-Fundação Calouste Gulbenkian.

Cerrillo, P. C. (2010). Sobre lectura, literatura y educación. Miguel Ángel Porrúa/Universidad de Castilla-La Mancha.

Cerrillo, P. C. (2016). El lector literario. Fondo de Cultura Económica.

Fillola, A. M. (2001). El intertexto lector. El espacio de encuentro de las aportaciones del texto con las del lector. CEPLI-UCLM.

Fillola, A. M. (2008). Función de la literatura infantil y juvenil en la formación de la competencia literaria. Biblioteca Virtual Miguel de Cervantes. http://www.shorturl.at/quJX7

Gomes, J. A. (2012). Prefácio. Em A. M. Ramos, Tendências contemporâneas da literatura portuguesa para a infância e a juventude (pp. 9-12) Tropelias \& Companhia.

Gomes, J. A. (2017). António Torrado: a oficina versátil. Em S. R. da Silva e J. M. Ribeiro (Orgs.), Contar de Novo a escrita para a infância de António Torrado (pp. 11-31). Tropelias e Companhia.

Gomes, J. A., Ramos, A. M., e Silva, S. R. da (2010). Reescritas do conto tradicional na literatura portuguesa para a infância e juventude (2000-2009). Em B.-A. Roig Rechou, I. Soto López e M. Neira Rodríguez (Coords.), Reescritas do Conto Popular (2000-2009) (pp. 33-46). Edições Xerais de Galicia.

Lluch, G. (2003). Uma proposta de análisis para el estúdio del lector modelo en la literatura infantil. Fundação Calouste Gulbenkian - Casa da Leitura. http://www.casadaleitura.org/portalbeta/bo/abz_indices/00 0735_PRO.pdf

Munita, F. (2014). El mediador escolar de lectura literaria: un estudio del espacio de encuentro entre prácticas didácticas, sistemas de creencias y trayectorias personales de lectura [Tese de doutoramento]. Universitat Autònoma de Barcelona. https://ddd.uab.cat/pub/tesis/2014/hdl_10803_313451/fm1de 1.pdf

Pires, M. N. (2007). A herança tradicional na literatura contemporânea. Editora Casa da Leitura. http://ww w.casadaleitura.org/portalbeta/bo/portal.pl?pag=abz_ot_detalhe\&id=43

Ramos, A. M. (2017). Interferências dramáticas na poesia para a infância de António Torrado: uma leitura como quem diz. En S. R. da Silva e J. M. Ribeiro (Orgs.), Contar de Novo a escrita para a infância de António Torrado (pp. 33-46). Tropelias e Companhia.

Robledo, B. H. (2017). El mediador de lectura. La formación del lector integral. IBBY Chile, Colección Alas de Colibrí. https://www.ibbychile.cl/2017/11/07/851/

Roig Rechou, B. A e Silva, S. R. (2017). Reescritas de textos da transmissão oral e literatura dramática. António Torrado na literatura infantil e juvenil Galega. Em S. R. da Silva e J. M. Ribeiro, João (Orgs.), Contar de Novo a escrita para a infância de António Torrado (pp. 137-150). Tropelias e Companhia.

Roig Rechou, B. A. (2013). Educação Literária e Literatura Infantojuvenil. Tropelias \& Companhia.

Roig Rechou, B. A. (2014). Autores imprescindíbeis de Kalandraka Editora. Em A. C. Macedo, E. A. Costas e S. R. da Silva (Coords.), Formación lectora. Obras imprescindíveis (pp. 145-155). Tropelias e Companhia.

Sáez, M. V. S. (2013). ¿Qué hacemos con los clásicos? Algunas reflexiones para los futuros docentes. Lenguaje y Textos, (38), 29-34. http://www.shorturl.at/fpKOR 
Sánchez-Fortún, J. M. A. (2003). Literatura Infantil: claves para la formación de la competencia literaria. Ediciones Aljibe.

Shavit, Z. (1986). Poetics of children's literature. University of Georgia Press.

Silva, M. M. T. (2017). Desafios para a leitura crítica da obra de António Torrado. Em S. R. da Silva e J. M. Ribeiro (Orgs.), Contar de Novo a escrita para a infância de António Torrado (pp. 57-69). Tropelias e Companhia.

Silva, S. R. da (2016). Capítulos da História da Literatura Portuguesa para a Infância. Tropelias e Companhia. Silva, V. M A. (2020). Teoria da Literatura. Livraria Almedina.

Souza, R. A. de (2014). História da Literatura. Trajetória, fundamentos, problemas. Realizações Editora.

Villanueva, D. (1994). Avances en Teoría de la Literatura (Estética de la Recepción, Pragmática, Teoría Empírica y Teoría de los Polisistemas). Universidade de Santiago de Compostela.

Villanueva, E. B. (2018). Competencia lectoliteraria y alfabetización en el siglo XXI. Em R. Tabernero-Sala (Ed.), Arte y oficio de ler obras infantiles (pp. 97-108). Octaedro.

Citar: Silva, S. R. da, Coladello Ferro, M. e Magalhães, M. H. (2021). A relevância do conhecimento da história da literatura para a infância no processo de mediação leitora. Elos. Revista de Literatura Infantil e Xuvenil, 8, “Artigos", 1-11. ISSN-e 2386-7620. DOI http://dx.doi.org/10.15304/elos.8.7975 